
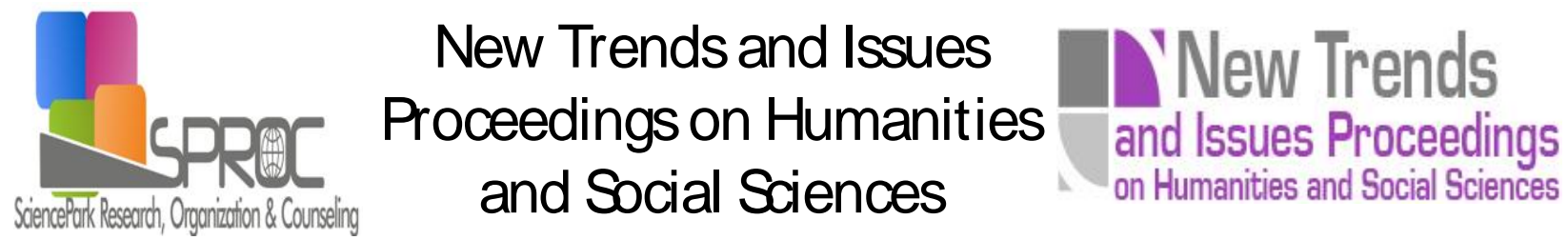

\title{
The New Learning Environment Meets the General Needs of the Students Teacher for a Day
}

Alina Teurculet *

Suggested Citation:

Abstract

educational styles is aimed at identifying effective style in relation to each educational context according to Fiedler's 
1. Introduction

- child' trust that will succeed in what he is trying; curiosity

2. Objectives of the study 


\section{Methodology}

\subsection{Procedure}

levels; the identification of students' half

fication of children'

monitoring students' verbal

\subsection{Participants}

3.3. Measures

e the students' emotional intelligence values consists

4. Results

4.1 Results Regarding Emotional Intelligence Values 
Table 1. The emotional intelligence (EI) values for children

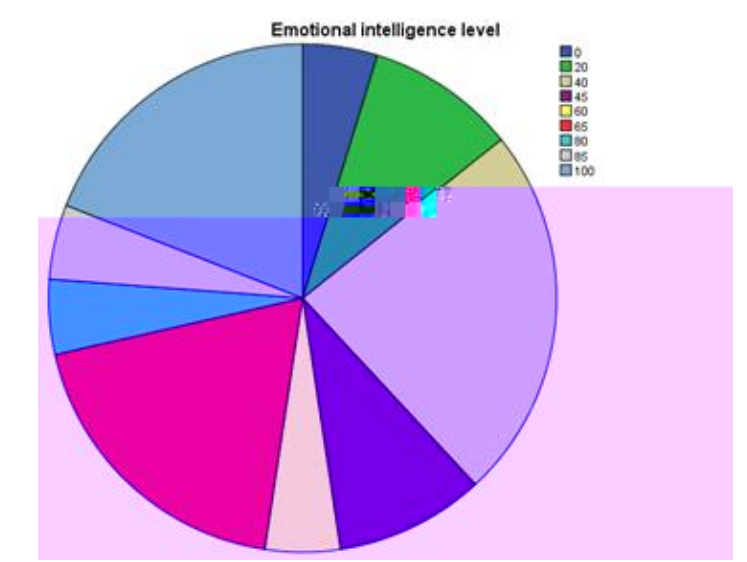

Figure 1. The emotional intelligence (EI) values for children

\subsection{Results Regarding Half-yearly Averages}

ents' performance. 

"Teacher for a day"

oriented solutions. The real outcomes of this process are not revealed by students' half needs. The real impact of this project is students' requirement to repeat the "Teacher for a day"

\section{Acknowledgements}

"Young successful $r$ professional development in an international and interdisciplinary environment".

\section{References}

$H$

Today's Children: Creating a Future for a Generation in Crisis. 


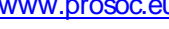

